\title{
Hypericum extract was as effective as imipramine but had fewer adverse effects in mild to moderate depression
}

Welk H for the Remotiv/Imipramine Study Group. Comparison of St John's wort and imipramine for treating depression: randomised controlled trial. BMJ 2000 Sep 2;321:536-9.

QUESTION: In patients with mild to moderate depression, how effective and safe is Hypericum perforatum (St John's wort) compared with imipramine?

\section{Design}

Randomised (allocation concealed*), blinded (patients)*, controlled trial with 6 weeks of follow up.

\section{Setting}

40 outpatient psychiatric, internal medicine, and general medicine clinics in Germany.

\section{Patients}

324 outpatients who were $\geqslant 18$ years of age (mean age $45 \mathrm{y}, 71 \%$ women) with mild to moderate depression (ICD-10 criteria) without increased suicidal ideation, and who had a score of $\geqslant 18$ on the 17 item Hamilton Depression Rating Scale (HDRS) on 2 consecutive visits. Exclusion criteria included pregnancy, allergy to the study drugs, abnormal thyroid function, bipolar disorder, serious psychiatric disease, and misuse of alcohol or drugs.

\section{Intervention}

157 patients were allocated to $75 \mathrm{mg}$ of imipramine twice daily, and 167 were allocated to $250 \mathrm{mg}$ of hypericum extract ZE 117 twice daily. Each group was also given placebos of the comparison treatment.

\section{Main outcome measures}

Change in scores on the HDRS, Clinical Global Impression Scale (CGIS), and Patient's Global Impression Scale (PGIS).

\section{Main results}

The 2 treatments were therapeutically equivalent with regard to overall effect on depression. The same improvement from baseline occurred with hypericum extract and imipramine at 6 weeks on the HDRS (least square mean change from baseline in HDRS score 12.0 $v 12.8,95 \%$ CI for the -0.8 difference -1.9 to 0.4 ), and similar mean scores were observed at 6 weeks on the CGIS (mean change $2.2 v 2.4$, CI for the 0.2 difference -0.4 to 0.02 ) and on the PGIS (mean change $2.4 v 2.6$, CI for the -0.2 difference -0.4 to 0.09 ). Response to treatment as measured by $a \geqslant 50 \%$ decrease on the HDRS was similar in the 2 groups (table). The study had a power of $90 \%$ to detect a difference in improvement between the groups of $>3.5$ points on the HDRS.

For correspondence: Dr H Wolk, Klinik fur

Psychiatrie und Psychotherapie, Akademisches

Lehrkrankenhaus der

Universitat Giessen,

Licher Strasse 106,

D-35394 Giessen,

Germany. Fax +49 (0)641403490.

\begin{tabular}{|c|c|c|c|}
\hline Hypericum & Imipramine & RBI (95\% Cl) & NNT (Cl) \\
\hline $43 \%$ & $40 \%$ & $8 \%(-4 \%$ to $17 \%)$ & Not significant \\
\hline
\end{tabular}

$\geqslant 50 \%$ decrease on the Hamilton Depression Rating Scale at 6 weeks comparing hypericum extract with imipramine in mild to ate depressiont
Patients tolerated hypericum extract better than imipramine $(\mathrm{p}<0.01)$. More patients in the imipramine group reported adverse effects and more patients withdrew because of adverse effects $(16 \% v 3 \%, \mathrm{p}<0.01)$.

\section{Conclusion}

In patients with mild to moderate depression, hypericum extract (St John's wort) was as effective as imipramine with fewer adverse effects.

*See glossary.

\section{COMMENTARY}

Previous studies of St John's wort indicate that it is an effective antidepressant when compared with placebo, ${ }^{1}$ but studies comparing it with other active treatments have often been of poor quality and criticised for using inadequate doses of antidepressants and for concentrating on relatively mild illness. ${ }^{2}$ To date this is the largest and best trial of St John's wort in depression and uses identical methodology to most antidepressant trials. Although the study does not mention the average dose of imipramine attained, they aimed to reach $150 \mathrm{mg} /$ day. The study was limited to patients with $I C D$ - 10 depressive episodes and scores of $\geqslant 18$ on the HDRS, which is the standard cut off for severity in antidepressant trials. The main finding is a familiar one-St John's wort is as effective as imipramine, but better tolerated.

While many will be heartened that a herbal remedy is as effective as a well established antidepressant, some caution is needed. In many countries (including the UK), St John's wort is not licensed and therefore is not subject to the same pre and post marketing surveillance used with conventional antidepressants. Several preparations of St John's wort are available each containing different doses of hypericum. Some reports suggest that it may interact with other medications-sometimes with disastrous consequences. More information is also required on safety in overdose. There may well now be sound reasons to welcome St John's wort as a new antidepressant, but the double standard whereby effective herbal remedies escape the rigours of licensing must end. ${ }^{4}$

Matthew Hotopf, MBBS, MRCPsych, MSc

Guy's, King's and St Thomas'School of Medicine and Institute of Psychiatry London, UK

1 Linde K, Ramirez G, Mulrow CD, et al. St John's wort for depression-an overview and meta-analysis of randomised clinical trials. BMJ 1996;313:253-8.

2 Maidment I. The use of St John's wort in the treatment of depression. Psychiatric Bulletin 2000;24:232-4.

3 Ruschitzka F, Meier PJ, Turina M, et al. Acute heart transplant rejection due to Saint John's wort. Lancet 2000;355:548-9.

4 Hotopf M. Sale of St John's wort. Psychiatric Bulletin 2000;24:352. 